\title{
SKF83959 is a novel triple reuptake inhibitor that elicits anti-depressant activity
}

\author{
Xing FANG ${ }^{1}$, Lin GUO ${ }^{1,}$, Jia JIA ${ }^{2}$, Guo-zhang $\mathrm{JIN}^{1}$, Bin ZHAO ${ }^{3}$, Yong-yong ZHENG ${ }^{4}$, Jian-qi $\mathrm{LI}^{4}$, Ao ZHANG ${ }^{1}$, Xue-chu \\ $\mathrm{ZHEN}^{1,2, *}$ \\ ${ }^{1}$ Department of Pharmacology II \& Synthetic Organic \& Medicinal Chemistry Laboratory, Shanghai Institute of Materia Medica, Chinese \\ Academy of Sciences, Shanghai 201203, China; ${ }^{2}$ Department of Pharmacology, College of Pharmaceutical Sciences, Soochow \\ University, Suzhou 215123, China; ${ }^{3}$ Department of Neurology, Affiliated Hospital of Guangdong Medical College, Zhanjiang 524001, \\ China; ${ }^{4}$ Novel Technology Center of Pharmaceutical Chemistry, Shanghai Institute of Pharmaceutical Industry, Shanghai 200437, \\ China
}

\begin{abstract}
Aim: SKF83959 (3-methyl-6-chloro-7,8-hydroxy-1-(3-methylphenyl)-2,3,4,5-tetrahydro-1H-3-benzazepine) is an atypical dopamine receptor-1 ( $D_{1}$ receptor) agonist, which exhibits many $D_{1}$ receptor-independent effects. In the present work, we examined the effects of SKF83959 on monoaminergic transporters in vitro and its anti-depressant activity in vivo.

Methods: Human serotonin transporter (SERT), norepinephrine transporters (NET) or dopamine transporters (DAT) were stably expressed in $\mathrm{CHO}$ cells. The uptake kinetics of SERT, NET, and DAT were examined using [ $\left.{ }^{3} \mathrm{H}\right]$-serotonin, $\left[{ }^{3} \mathrm{H}\right]-$ norepinephrine or $\left[{ }^{3} \mathrm{H}\right]$-dopamine, respectively. A triple reuptake inhibitor DOV21947 was used as the positive control. Tail suspension test and forced swimming test were conducted in mice. SKF83959 or DOV21947 (2-8 mg/kg) were intraperitoneally injected $30 \mathrm{~min}$ before the tests. Results: SKF83959 was a competitive inhibitor of SERT $\left(K_{\mathrm{i}}=1.43 \pm 0.45 \mu \mathrm{mol} / \mathrm{L}\right)$, but a noncompetitive inhibitor of NET $\left(K_{\mathrm{i}}=0.60 \pm 0.07\right.$ $\mu \mathrm{mol} / \mathrm{L})$ and DAT $\left(K_{\mathrm{i}}=9.01 \pm 0.80 \mu \mathrm{mol} / \mathrm{L}\right)$. In contrast, DOV21947 was a competitive inhibitor of SERT $\left(K_{\mathrm{i}}=0.89 \pm 0.24 \mu \mathrm{mol} / \mathrm{L}\right)$ and DAT $\left(K_{i}=1.47 \pm 0.31 \mu \mathrm{mol} / \mathrm{L}\right)$ and a noncompetitive inhibitor of NET $\left(K_{i}=0.18 \pm 0.04 \mu \mathrm{mol} / \mathrm{L}\right)$. In mice, both SKF83959 and DOV21947 elicited anti-depressant activity in a dose-dependent manner.

Conclusion: SKF83959 functions as a novel triple reuptake inhibitor in vitro and exerts anti-depressant effects in vivo.
\end{abstract}

Keywords: SKF83959; monoamine transporter; serotonin; norepinephrine; dopamine; depression; DOV21947

Acta Pharmacologica Sinica (2013) 34: 1149-1155; doi: 10.1038/aps.2013.66; published online 29 Jul 2013

\section{Introduction}

Depression is a severe and chronic mental disorder that affects a large population worldwide ${ }^{[1,2]}$. The development of effective anti-depressants with less adverse effects remains a challenge in pharmaceutical research. Within the past few decades, biogenic amine uptake inhibitors have been the mainstay for the treatment of depression, such as the prototypical tricyclic anti-depressants, the selective serotonin uptake inhibitors and the so-called "second" generation dual serotonin/ norepinephrine uptake inhibitors with a "cleaner" side effect profile $^{[3]}$.

Despite these advances, all these drugs often require 3 weeks to take effect. Moreover, nearly $30 \%-40 \%$ of patients

\footnotetext{
* To whom correspondence should be addressed.

E-mail guolin0724@163.com (Lin GUO); zhenxuechu@suda.edu.cn (Xue-chu ZHEN)

Received 2013-02-01 Accepted 2013-04-22
}

with depression were not responsive to these therapies ${ }^{[4]}$. Recent studies have shown that a compound producing an immediate increase in synaptic dopamine concentrations would result in a more rapid onset of relief and a shortening or elimination of the therapeutic lag $^{[5]}$. Thus, triple uptake inhibitors have become a focal point in anti-depressant drug development. Furthermore, some of these drugs have shown promising responses in clinical trials ${ }^{[6-9]}$.

The atypical dopamine receptor- 1 ( $\mathrm{D}_{1}$ receptor) agonist, 3-methyl-6-chloro-7,8-hydroxy-1-[3-methylphenyl]-2,3,4,5tetrahydro-1H-3-benzazepine (SKF83959) has shown various biological functions in vitro and in intact animals. Unlike the typical $D_{1}$ receptor agonists, SKF83959 does not stimulate the production of cyclic adenosine monophosphate (cAMP) via $D_{1}$-like receptor-mediated activation of the $G_{s}$ protein ${ }^{[10-13]}$; instead, it selectively activates the $G_{q}$ protein via the $\mathrm{D}_{1}$-like receptor, which results in the production of inositol triphosphate $\mathrm{e}^{[14-20]}$. In animals, this drug was found to increase 
eye blinking in monkeys and rats and to elicit excellent antiParkinsonism effects in a primate model as well as in a unilateral-lesioned rodent model ${ }^{[21-23]}$. The anti-Parkinsonism effects were shown to be independent of $D_{1}$ dopamine receptor-stimulated cAMP and may be associated with the drug-activated $\mathrm{G}_{\mathrm{q}} /$ phospholipase $C$ pathway ${ }^{[23,24]}$.

In addition to the receptor-mediated events, recent data also indicated that the $\mathrm{D}_{1}$ receptor-independent pharmacological effects also played important roles in SKF83959-mediated biological responses. For example, we found that potent neuronal protection of the drug was only partially dependent on the $\mathrm{D}_{1}$ receptor ${ }^{[25]}$ and that SKF83959 blocked $\mathrm{Na}^{+}$channels ${ }^{[26]}$, modulated the delayed rectifier $\mathrm{K}^{+}$channels ${ }^{[27]}$ and promoted the spontaneous release of glutamate in rat somatosensory cortical neurons ${ }^{[28]}$.

In the present work, we examined whether SKF83959 effectively inhibited the uptake activity of the serotonin transporter (SERT), norepinephrine transporter (NET) and dopamine transporter (DAT), by functioning as a potent triple uptake inhibitor. Moreover, we also examined the anti-depressant activity of SKF83959 in vivo.

\section{Materials and methods Animals}

Male C57BL/6J mice, weighing 18-20 g, were purchased from Shanghai Laboratory Animal Co, Ltd (Shanghai, China) and were housed in plastic cages (temperature: $21 \pm 1^{\circ} \mathrm{C}$ ) with air exchange every $20 \mathrm{~min}$ and an automatic $12 \mathrm{~h}$ light/dark cycle (light on from 7:00 AM to 19:00 PM). The animals were fed a standard laboratory diet, and water was provided ad libitum. All the experimental protocols were approved by the Institutional Animal Care and Use Committee of Shanghai Institute of Materia Medica, Chinese Academy of Sciences (SIMM-201106-ZXC-07) and were in compliance with the Guidelines for the Care and Use of Laboratory Animals (National Research Council, China, 1996).

\section{Drugs and chemicals}

$( \pm)$-SKF83959 was synthesized in the Synthetic Organic \& Medicinal Chemistry Laboratory, Shanghai Institute of Materia Medica, Chinese Academy of Sciences (Shanghai, China). (1R,5S)-(+)-1-(3,4-Dichlorophenyl)-3-azabicyclo[3.1.0] hexane hydrochloride (DOV21947) was supplied by the Novel Technology Center of Pharmaceutical Chemistry, Shanghai Institute of Pharmaceutical Industry. $\left[{ }^{3} \mathrm{H}\right]$-serotonin, $\left[{ }^{3} \mathrm{H}\right]-$ dopamine and $\left[{ }^{3} \mathrm{H}\right]$-norepinephrine were purchased from PerkinElmer Inc (Waltham, MA, USA). Pargyline, tropolone and ascorbic acid were obtained from Sigma-Aldrich Co (St Louis, MO, USA). SKF83959, pargyline, tropolone and DOV21947 were dissolved in dimethyl sulfoxide at a concentration of $100 \mathrm{mmol} / \mathrm{L}$ stock solution. Prior to the experiments, the stock solutions were diluted with Hanks' Balanced Salt Solution (HBSS) buffer ( $\mathrm{NaCl} 140 \mathrm{mmol} / \mathrm{L}, \mathrm{KCl} 5.4 \mathrm{mmol} /$ $\mathrm{L}, \mathrm{KH}_{2} \mathrm{PO}_{4} 0.4 \mathrm{mmol} / \mathrm{L}, \mathrm{NaHCO}_{3} 4.2 \mathrm{mmol} / \mathrm{L}, \mathrm{Na}_{2} \mathrm{HPO}_{4} 0.3$ $\mathrm{mmol} / \mathrm{L}, \mathrm{D}$-glucose $5.5 \mathrm{mmol} / \mathrm{L}, \mathrm{pH} 7.2-7.4)$ to the designated concentrations $(0.1 \mathrm{nmol} / \mathrm{L}-0.1 \mathrm{mmol} / \mathrm{L})$.

\section{The inhibitory effects of SKF83959 on SERT, NET, and DAT}

Stably expressed transporter Chinese hamster ovary $(\mathrm{CHO})$ cell lines were generated in our laboratory and have been previously used for compound activity tests ${ }^{[29]}$. These stablyexpressed transporter cell lines were cultured in a mixture of Dulbecco's modified Eagle's medium (DMEM) and F12 (1:1, $v / v)$ supplemented with $10 \%$ fetal calf serum (FCS) and antibiotics (10 units/mL penicillin, $100 \mathrm{\mu g} / \mathrm{mL}$ streptomycin, and $100 \mu \mathrm{g} / \mathrm{mL}$ G418). The culture dishes were maintained in a $37^{\circ} \mathrm{C}$ incubator with a humidified atmosphere of $5 \% \mathrm{CO}_{2}$.

We first investigated the inhibitory effects of SKF83959 on the uptake activity of SERT. The assays were performed as previously described ${ }^{[30]}$. Briefly, SERT-expressing $\mathrm{CHO}$ cells were seeded in 24-well cluster plates (Corning; NY, USA) at a density of $1.0 \times 10^{6}$ cells per well. After $12 \mathrm{~h}$, the culture medium was removed, and $20 \mu \mathrm{L}$ of SKF83959 or DOV21947 (final concentration: $0.1 \mathrm{nmol} / \mathrm{L}-0.1 \mathrm{mmol} / \mathrm{L}$ ) and $160 \mu \mathrm{L}$ HBSS buffer (containing $10 \mu \mathrm{mol} / \mathrm{L}$ pargyline, $10 \mu \mathrm{mol} / \mathrm{L}$ tropolone, and $10 \mu \mathrm{mol} / \mathrm{L}$ ascorbic acid) were added. After 10 min of incubation, $\left[{ }^{3} \mathrm{H}\right]$-serotonin was added (final concentration: $2.4 \mathrm{nmol} / \mathrm{L}$ ) for $10 \mathrm{~min}$ at $37^{\circ} \mathrm{C}$. The uptake was terminated by rinsing the cells three times with ice-cold PBS buffer. The cells were lysed using $0.1 \mathrm{~mL}$ of $2 \mathrm{~mol} / \mathrm{L} \mathrm{NaOH}$. Nonspecific uptake was defined with $\mathrm{Na}^{+}$-free HBSS. The general procedures for norepinephrine and dopamine uptake were the same as those used for serotonin except for the different radiolabeled ligands ${ }^{[29]}$.

To further characterize the effects of SKF83959, we analyzed the kinetics of SKF83959 and DOV21947 on the corresponding transporters. For the $K_{\mathrm{t}}$ measurement, the corresponding cells were incubated with different concentrations of radiolabeled ligand $\left(\left[{ }^{3} \mathrm{H}\right]\right.$-serotonin: $1.2-1280 \mathrm{nmol} / \mathrm{L} ;\left[{ }^{3} \mathrm{H}\right]$-norepinephrine: 1.4-45 nmol/L; $\left[{ }^{3} \mathrm{H}\right]$-dopamine: $\left.1.6-100 \mathrm{nmol} / \mathrm{L}\right)$. The uptake was then performed as previously described. The $K_{\mathrm{t}}$ values of the transporters were estimated using the Michaelis-Menten equation:

$$
V=\frac{V_{\max } \cdot S}{K_{\mathrm{t}}+S}
$$

where $S$ denotes the radiolabeled ligand concentration (nmol/L), $V_{\max }$ denotes the maximal reuptake capacity $\left(\mathrm{cpm} / \mathrm{min} \cdot 10^{6} \mathrm{cell}\right)$, and $K_{\mathrm{t}}$ denotes the Michaelis-Menten constant for the transporter-mediated transport (nmol/L).

Next, the $K_{\mathrm{i}}$ parameter was assayed. The saturation curves were re-examined in the presence of SKF83959 or DOV21947. Depending on the inhibitory pattern (competitive or noncompetitive), the $K_{\mathrm{i}}$ values were then calculated using the Michaelis-Menten competitive inhibition equation:

$$
V=\frac{V_{\max } \cdot S}{K_{\mathrm{t}}\left(1+\frac{\mathrm{I}}{K_{\mathrm{i}}}\right)+S}
$$

or noncompetitive inhibition equation:

$$
V=\frac{V_{\max } \cdot S}{\left(K_{\mathrm{t}}+S\right)\left(1+\frac{\mathrm{I}}{K_{\mathrm{i}}}\right)}
$$


where $S$ denotes the radiolabeled ligand concentration $(\mathrm{nmol} / \mathrm{L}), V_{\max }$ denotes the maximal reuptake capacity $(\mathrm{cpm} /$ $\min \cdot 10^{6}$ cell), I denotes the concentration of SKF83959 or DOV21947 $(\mu \mathrm{mol} / \mathrm{L})$, and $K_{\mathrm{i}}$ denotes the inhibition constant of SKF83959 or DOV21947 for the transporters $(\mu \mathrm{mol} / \mathrm{L})$.

\section{Forced swimming test}

The forced swimming test was performed as previously described ${ }^{[31]}$. The mice were placed in a transparent cylindrical beaker (height, $\sim 25 \mathrm{~cm}$; internal diameter, $10 \mathrm{~cm}$ ) containing water $\left(22-24^{\circ} \mathrm{C}\right)$ to a level of $15 \mathrm{~cm}$. The water was always changed between trials. Thirty minutes before the test, SKF83959 or DOV21947 was intraperitoneally administered $(2-8 \mathrm{mg} / \mathrm{kg}$ ) to the mice. The immobility time was measured during a 5-min period by a trained observer who was blind to the treatment conditions. Each mouse was considered immobile if they were floating motionless or if they were only making the minimal amount of movements necessary to keep its head above the water surface.

\section{Tail-suspension test}

The tail suspension test was performed as previously described $^{[32]}$. C57BL/6J mice were individually suspended 75 $\mathrm{cm}$ above the tabletop with an adhesive tape placed approximately $1 \mathrm{~cm}$ from the tip of the tail. The immobility duration was recorded for $6 \mathrm{~min}$. Thirty minutes before the test, SKF83959 or DOV21947 was intraperitoneally administered $(2-8 \mathrm{mg} / \mathrm{kg})$. The duration of the immobility was measured by a trained observer according to the double-blind test rule. The mice were considered immobile only if they were hung passively and demonstrated no motion.

\section{Data analysis}

The $\mathrm{IC}_{50}$ values were expressed as the mean [95\% confidence interval $(95 \% \mathrm{CI})]$. The difference between the $\mathrm{IC}_{50}$ was tested using weighted probit analysis. The other data were expressed as the mean $\pm S E M$. For multiple comparisons of the parameters, one-way ANOVA and the Dunnett's post-hoc test were used. Differences were considered significant if $P<0.05$. The data were analyzed using the Graphpad Prism software (GraphPad Software Inc, La Jolla, CA, USA, Version 5.0).

\section{Results}

\section{Inhibition of SKF83959 on SERT, NET, and DAT}

First, we tested the maximal inhibitory effect of SKF83959 on the three transporters. We found that SKF83959 (100 $\mu \mathrm{mol} / \mathrm{L})$ completely blocked the uptake activity. Moreover, the maximal inhibitory effect of SKF83959 was similar to that of DOV21947 ( $t$-test, $P>0.05$ ).

Next, we studied the concentration-response relationship for SKF83959-inhibited uptake activity on the respective transporter. As shown in Figure 1 and Table 1, the $\mathrm{IC}_{50}$ of SKF83959 for SERT was similar to that of DOV21947 ( $t$-test, $P>0.05$ ), but the $\mathrm{IC}_{50}$ values of SKF83959 for NET and DAT were greater than those of DOV21947 ( $t$-test, $P<0.05$ ).

These data clearly demonstrated that SKF83959 functions as a potent triple reuptake inhibitor.

\section{Effects of SKF83959 on the uptake kinetics of SERT, NET, and DAT}

To further characterize the effects of SKF83959 on the three transporters, we analyzed the kinetics of the transporters and checked the effect of SKF83959 on the uptake kinetics. The relationship between the uptake activity and the substrate concentration was provided by the Michaelis-Menten equation.

As shown in Figure 2A and Table 2, SKF83959 and DOV21947 did not alter $V_{\max }$ (one-way ANOVA, $P>0.05$ ), but significantly increased the value of $K_{\mathrm{t}}$ (one-way ANOVA, $P<0.05)$, indicating that SKF83959 and DOV21947 were two competitive inhibitors for SERT. Moreover, the $K_{\mathrm{i}}$ value of SKF83959 was not significantly different from that of DOV21947 ( $t$-test, $P>0.05$ ).

However, in contrast to the effect on SERT, both SKF83959 and DOV21947 reduced the $V_{\max }$ value (one-way ANOVA, $P<0.05$, compared to vehicle) but did not change the $K_{\mathrm{t}}$ value (one-way ANOVA, $P>0.05$, compared to vehicle) in the NET uptake kinetics test, which was consistent with its noncompetitive pattern (Figure 2B, Table 2). The $K_{\mathrm{i}}$ of SKF83959 was greater than that of DOV21947 ( $t$-test, $P<0.05$ ), indicating that the inhibitory activities of SKF83959 were weaker than that of DOV21947.

Similar to NET, SKF83959 also inhibited DAT in a noncompetitive manner. SKF83959 significantly decreased $V_{\max }(t$-test, $P<0.05)$ without any change in $K_{\mathrm{t}}(t$-test, $P>0.05)$. Interestingly, in contrast to SKF83959, DOV21947 inhibited DAT in a competitive manner (Figure 2C, Table 2). The $K_{\mathrm{i}}$ of SKF83959 was greater than that of DOV21947 ( $t$-test, $P<0.05)$, indicating that the inhibitory activities of SKF83959 were weaker than that of DOV21947.

\section{SKF83959 elicits potent anti-depressant activity in animal models}

Because SKF83959 is a novel potent triple reuptake inhibitor, we tested the anti-depressant activity of this drug in mice. The forced swimming and tail suspension tests are two widely used methods to detect the anti-depressant efficacy of experimental drugs.

As shown in Figure 3A, SKF83959 decreased the immobility time in the forced swimming test in a dose-dependent manner. For the vehicle treated-mice, the immobility time was $158.40 \pm 10.31 \mathrm{~s}$. The immobility time was significantly decreased (one-way ANOVA, $P<0.001$ ) in mice treated with SKF83959. Importantly, the reductions in the immobility time produced by SKF83959 were comparable to that produced by DOV21947 at the same doses (Figure 3A).

Similarly, SKF83959 significantly reduced the immobility time in the tail suspension test (Figure 3B, one-way ANOVA, $P<0.001)$. In the vehicle group, the immobility time was $135.00 \pm 7.44 \mathrm{~s}$. A significant decrease was observed with 2 $\mathrm{mg} / \mathrm{kg}$ of SFK83959 treatment. Furthermore, the reductions in the immobility time produced by SKF83959 were comparable to those in the immobility time produced by DOV21947 at the same doses (Figure 3B). 

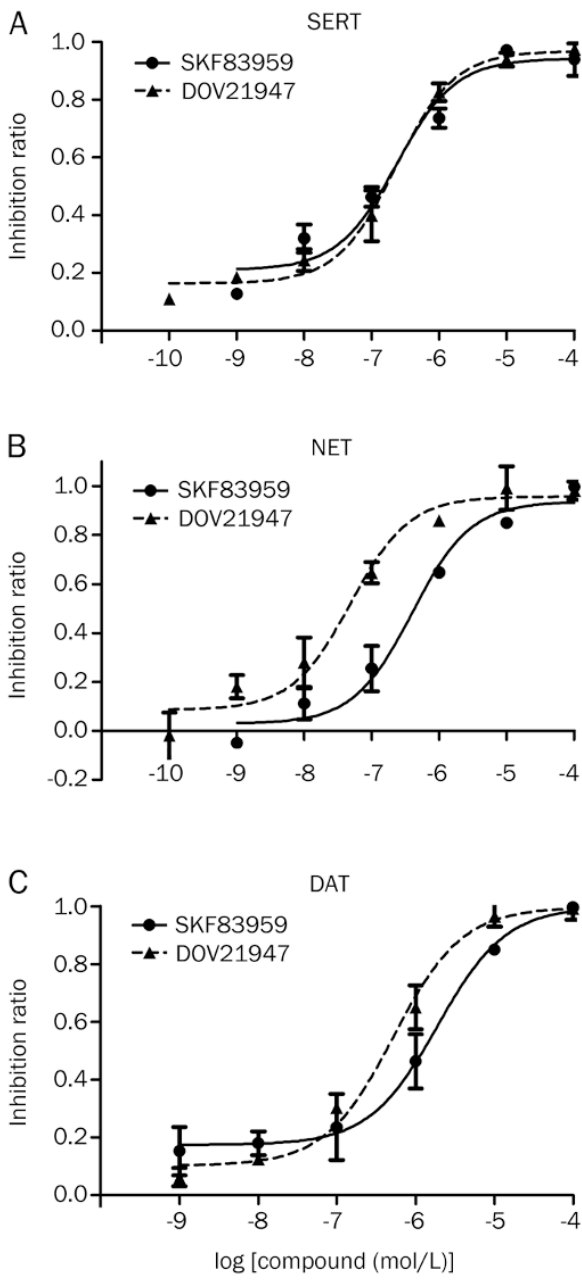

Figure 1. The concentration-response curves of SKF83959 and DOV21947 on SERT, NET, and DAT. The uptake assays were performed as described in the Methods section. Various concentrations of SKF83959 or DOV21947 were incubated with $\left[{ }^{3} \mathrm{H}\right]$-radiolabeled ligand for $10 \mathrm{~min}$. The final concentration of $\left[{ }^{3} \mathrm{H}\right]$-serotonin was $2.4 \mathrm{nmol} / \mathrm{L}$, $\left[{ }^{3} \mathrm{H}\right]$-norepinephrine was $1.4 \mathrm{nmol} / \mathrm{L}$ and $\left[{ }^{3} \mathrm{H}\right]$-dopamine was $1.6 \mathrm{nmol} / \mathrm{L}$. The nonspecific uptake activity was determined using $\mathrm{Na}^{+}$-free HBSS solution and the specific uptake activity was normalized as $100 \%$. Each experiment was replicated at least three times. The data were expressed as the mean \pm SEM.

\section{Discussion}

In the present study, we found that SKF83959 was an effective inhibitor for the uptake activity of SERT, NET, and DAT. We further determined that SKF83959 functioned as a SERT competitive inhibitor, and behaved as a noncompetitive inhibitor for NET and DAT, which differed from the well-known triple uptake inhibitor DOV21947. Moreover, we provided convincing data demonstrating that SKF83959 was a potent antidepressant agent in the forced swimming test and tail suspension test in mice. The present study showed, for the first time, that SKF83959 is a novel triple uptake inhibitor that elicits an anti-depressant effect. This finding may provide a novel pharmacological mechanism for the understanding of various biological functions of this drug.
Table 1. Effects of SKF83959 and DOV21947 on the uptake activity of SERT, NET, and DAT.

\begin{tabular}{llll}
\hline & & \multicolumn{2}{c}{ Compound } \\
& & \multicolumn{1}{c}{ DOV21947 } & \multicolumn{1}{c}{ SKF83959 } \\
\hline \multirow{2}{*}{ SERT } & Maximal inhibiting ratio & $95.10 \% \pm 1.55 \%$ & $97.35 \% \pm 0.78 \%$ \\
& $\mathrm{IC}_{50}(95 \% \mathrm{Cl})(\mathrm{nmol} / \mathrm{L})$ & $187(100-533)$ & $242(148-346)$ \\
NET & Maximal inhibiting ratio & $99.65 \% \pm 0.39 \%$ & $98.14 \% \pm 2.17 \%$ \\
& $\mathrm{IC}_{50}(95 \% \mathrm{Cl})(\mathrm{nmol} / \mathrm{L})$ & $93.5(22.3-101)$ & $381(233-672)^{\mathrm{b}}$ \\
DAT & Maximal inhibiting ratio & $99.45 \% \pm 0.74 \%$ & $99.20 \% \pm 2.28 \%$ \\
& $\mathrm{IC}_{50}(95 \% \mathrm{Cl})(\mathrm{nmol} / \mathrm{L})$ & $533(335-828)$ & $1375(1140-3170)^{\mathrm{b}}$ \\
\hline
\end{tabular}

The parameters were obtained from Figure 1 . The values of $I_{50}$ were expressed as mean [95\% confidence interval $(95 \% \mathrm{Cl})]$. The difference between $\mathrm{IC}_{50}$ was tested by weighted probit analysis. Maximal Inhibiting ratio was expressed as mean $\pm S E M$. The nonspecific uptake activity was defined using $\mathrm{Na}^{+}$-free HBSS. ${ }^{\mathrm{b}} \mathrm{P}<0.05$ vs DOV21947.

Increasing the synaptic availability of biogenic amines is one important strategy used in anti-depressant therapy ${ }^{[33]}$. Following the application of dual uptake inhibitors (prototypic tricyclic anti-depressants and serotonin/norepinephrine uptake inhibitors) and the selective serotonin uptake inhibitor, triple uptake inhibitors were recently found to be promising chemical entities for the treatment of depression ${ }^{[34]}$, including DOV21947, PRC200SS, and GSK136070F. DOV21947 has demonstrated effective anti-depressant activity in a Phase III clinical study ${ }^{[34]}$. In addition, the most recent clinical studies have shown that DOV21947 begins to exert its anti-depressant activity after only one week of treatment ${ }^{[35]}$. The mean baseline score on the Montgomery-Åsberg Depression Rating Scale (MADRS) was significantly higher than that on the placebotreated population. Our data indicated that SKF83959, with a benzazepine structure, is a novel and potent triple uptake inhibitor that elicits a comparable anti-depressant efficacy in vivo similar to DOV21947. Due to the difficulty in the design of triple uptake inhibitors ${ }^{[36]}$, the identification of a benzazepine-like structure as a novel category of triple uptake inhibitor may provide an alternative strategy in the development of anti-depressant drugs.

Analysis of the transporting kinetics of SKF83959 and DOV21947 revealed a significant difference between the two types of uptake inhibitors. We found that SKF83959 was a competitive inhibitor for SERT, but a noncompetitive inhibitor for NET and DAT. Consistent with previous reports ${ }^{[6]}$, we confirmed that DOV12947 was a competitive uptake inhibitor for DAT and SERT. Interestingly, we found that DOV21947 was a NET noncompetitive inhibitor, which has not been previously reported. Moreover, our data showed that the inhibitory potency of SKF83959 on SERT was similar to DOV21947, but was weaker on NET and DAT. Despite this difference, the same dose of SKF83959 and DOV21947 produced equivalent anti-depressant effects in different animal models (Figure 3). However, whether the differential inhibitory patterns in the kinetics between the two drugs contribute to the anti-depres- 

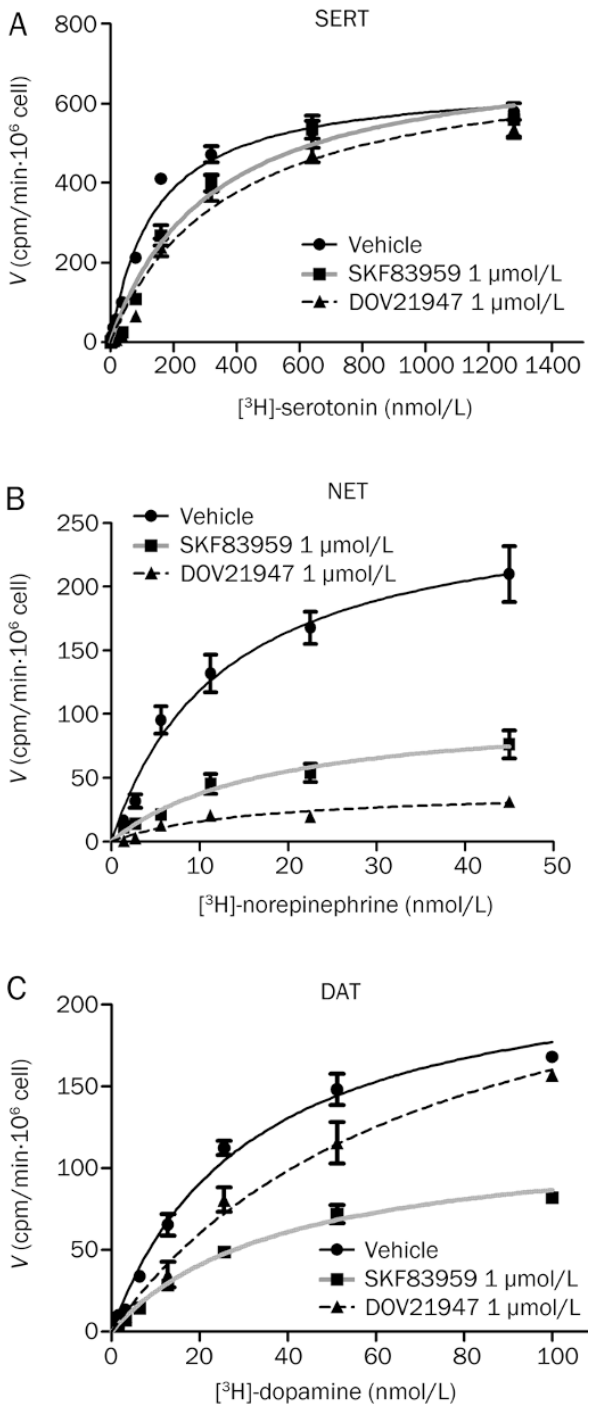

Figure 2. The effects of SKF83959 and DOV21947 on the transporting kinetics of SERT, NET, and DAT. The kinetics was assayed using $\left[{ }^{3} \mathrm{H}\right]-$ serotoin, $\left[{ }^{3} \mathrm{H}\right]$-norepinephrine, or $\left[{ }^{3} \mathrm{H}\right]$-dopamine in the presence of vehicle, SKF83959 or DOV21947. The nonspecific uptake activity was determined using $\mathrm{Na}^{+}$-free HBSS solution. Each experiment was replicated at least three times. The data were expressed as the mean \pm SEM.
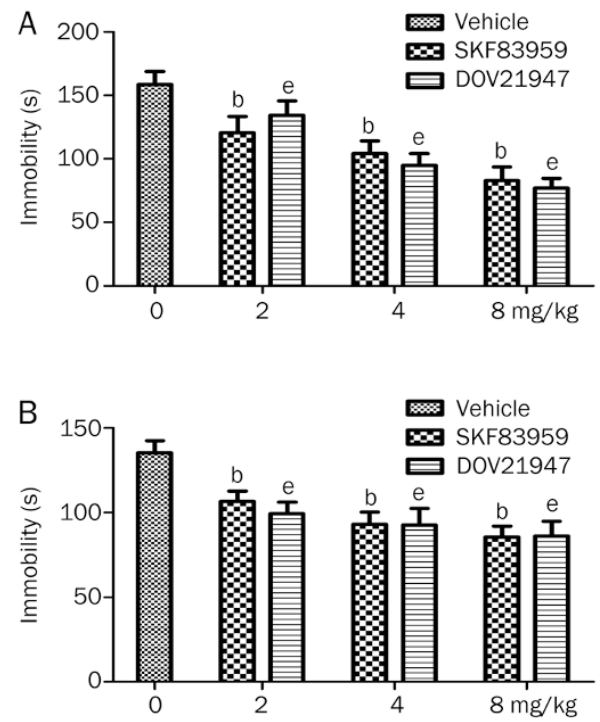

Figure 3. Effects of SKF83959 on immobility in the forced swimming test and the tail suspension test. The behavioral assays were performed as described in the Methods section. Each experimental group contained 10 animals. (A) Forced swimming test. (B) Tail suspension test. The data were presented as the mean \pm SEM and analyzed using one-way ANOVA analysis followed by Dunnett's post-hoc test. ${ }^{\mathrm{b}} P<0.05$, ${ }^{\mathrm{e}} P<0.05$ vs the vehicle group.

sant response remains unknown.

It appears that the $\mathrm{IC}_{50}$ and $K_{\mathrm{i}}$ values in our experiments were greater than those previously reported by Skolnick et al. In fact, our experiment was completely different from that of Skolnick ${ }^{[6]}$. Our experiment was based on uptake kinetics, whereas that of Skilnick was based on receptor binding. Thus, the $K_{\mathrm{i}}$ values between the two studies were completely different although they share a common symbol $\left(K_{\mathrm{i}}\right)$. In addition, the difference in the cell lines used (CHO vs HEK293) may also account for the discrepancy. It is well known that the $\mathrm{IC}_{50}$ value is closely dependent on the transporter density in the cell membrane as well as the expression level of the transporters. In addition, the difference in the transporters of the species employed (human transporter and rat transporter) also

Table 2. Effects of SKF83959 and DOV21947 on the transporting kinetics of SERT, NET, and DAT.

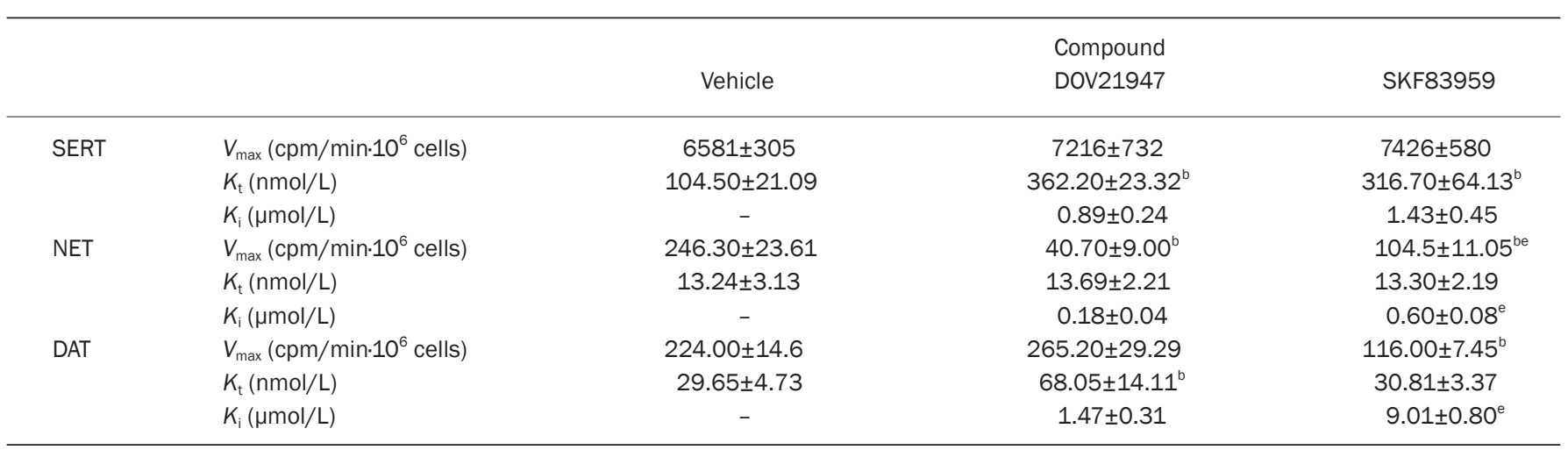

The parameters were obtained from Figure 2. Data were expressed as mean \pm SEM. ${ }^{\mathrm{b}} P<0.05$ vs vehicle. ${ }^{\mathrm{e}} P<0.05$ vs DOV21947. 
produced some distinct potency in the in vitro cell models ${ }^{[10]}$.

In summary, the present data indicated that SKF83959 displayed potent anti-depressant effects. The identification of SKF83959, a benzazepine structure, as a triple uptake inhibitor may provide a new avenue for the discovery of novel antidepressant drugs.

\section{Acknowledgements}

This work was financially supported by grants obtained from the National Natural Science Foundation of China (81130023, 81100918, and 81271214), National Basic Research Plan (973) of the Ministry of Science and Technology of China (2009CB522000 and 2011CB5C4403). We also appreciate the support provided by the Priority Academic Program Development of Jiangsu Higher Education Institutes (PAPD) and a grant obtained from the Jiangsu Science and Technology Commission (BY2011131).

\section{Author contribution}

Xing FANG, Lin GUO, Xue-chu ZHEN, and Bin ZHAO designed the research; Lin GUO, Xing FANG, and Jia JIA performed the research; Yong-yong ZHENG, Jian-qi LI, and Ao ZHANG contributed new reagents and discussed the results; Guo-zhang JIN and Xing FANG analyzed the data; and Lin GUO and Xue-chu ZHEN wrote the manuscript.

\section{References}

1 Belmaker RH, Agam G. Major depressive disorder. N Engl J Med 2008; 358: 55-68.

2 Duman RS. Neuronal damage and protection in the pathophysiology and treatment of psychiatric illness: stress and depression. Dialogues Clin Neurosci 2009; 11: 239-55.

3 Millan MJ. The role of monoamines in the actions of established and "novel" antidepressant agents: a critical review. Eur J Pharmacol 2004; 500: 371-84.

4 Kulkarni SK, Dhir A. Current investigational drugs for major depression. Expert Opin Investig Drugs 2009; 18: 767-88.

5 Skolnick P, Popik P, Janowsky A, Beer B, Lippa AS. "Broad spectrum" antidepressants: is more better for the treatment of depression? Life Sci 2003; 73: 3175-9.

6 Skolnick P, Popik P, Janowsky A, Beer B, Lippa AS. Antidepressant-like actions of DOV 21,947: a "triple" reuptake inhibitor. Eur J Pharmacol 2003; 461: 99-104.

7 Breuer ME, Chan JS, Oosting RS, Groenink L, Korte SM, Campbell $\mathrm{U}$, et al. The triple monoaminergic reuptake inhibitor DOV 216,303 has antidepressant effects in the rat olfactory bulbectomy model and lacks sexual side effects. Eur Neuropsychopharmacol 2008; 18 : 908-16.

8 Liang Y, Shaw AM, Boules M, Briody S, Robinson J, Oliveros A, et al. Antidepressant-like pharmacological profile of a novel triple reuptake inhibitor, (1S,2S)-3-(methylamino)-2-(naphthalen-2-yl)-1-phenylpropan1-ol (PRC200-SS). J Pharmacol Exp Ther 2008; 327: 573-83.

9 Aluisio L, Lord B, Barbier AJ, Fraser IC, Wilson SJ, Boggs J, et al. Invitro and in-vivo characterization of JNJ-7925476, a novel triple monoamine uptake inhibitor. Eur J Pharmacol 2008; 587: 141-6.

10 Andringa G, Drukarch B, Leysen JE, Cools AR, Stoof JC. The alleged dopamine $D_{1}$ receptor agonist SKF 83959 is a dopamine $D_{1}$ receptor antagonist in primate cells and interacts with other receptors. Eur J
Pharmacol 1999; 364: 33-41.

11 Makihara Y, Okuda Y, Kawada C, Matsumoto M, Waddington JL, Koshikawa $\mathrm{N}$, et al. Differential involvement of cyclase-versus noncyclase-coupled $D_{1}$-like dopamine receptors in orofacial movement topography in mice: studies with SKF 83822. Neurosci Lett 2007; 415: 6-10.

12 Rashid AJ, O'Dowd BF, Verma V, George SR. Neuronal G $\mathrm{q}_{\mathrm{q}}$ 11-coupled dopamine receptors: an uncharted role for dopamine. Trends Pharmacol Sci 2007; 28: 551-5.

13 Fujita S, Kiguchi M, Kobayashi M, Kinsella A, Koshikawa N, Waddington JL. Assessment of jaw movements by magnetic sensor in relation to topographies of orofacial behaviour in freely moving rats: Studies with the dopamine $D_{1}$-like receptor agonists SKF 83822 vs SKF 83959. Eur J Pharmacol 2010; 632: 39-44.

14 Panchalingam S, Undie AS. SKF83959 exhibits biochemical agonism by stimulating $\left[{ }^{35} \mathrm{~S}\right]$ GTP gamma $\mathrm{S}$ binding and phosphoinositide hydrolysis in rat and monkey brain. Neuropharmacology 2001; 40: 826-37.

15 Cools AR, Lubbers L, van Oosten RV, Andringa G. SKF83959 is an antagonist of dopamine $D_{1}$-like receptors in the prefrontal cortex and nucleus accumbens: a key to its antiparkinsonian effect in animals? Neuropharmacology 2002; 42: 237-45.

16 Jin LQ, Goswami S, Cai G, Zhen X, Friedman E. SKF83959 selectively regulates phosphatidylinositol-linked $D_{1}$ dopamine receptors in rat brain. J Neurochem 2003; 85: 378-86.

17 O'Sullivan GJ, Clifford JJ, Tomiyama K, Koshikawa N, Drago J, Sibley $\mathrm{DR}$, et al. $\mathrm{D}_{1}$-like dopamine receptor-mediated function in congenic mutants with $D_{1}$ vs $D_{5}$ receptor "knockout". J Recept Signal Transduct Res 2004; 24: 107-16.

18 Sahu A, Tyeryar KR, Vongtau HO, Sibley DR, Undieh AS. $D_{5}$ dopamine receptors are required for dopaminergic activation of phospholipase $\mathrm{C}$. Mol Pharmacol 2009; 75: 447-53.

19 Ming Y, Zhang $\mathrm{H}$, Long L, Wang F, Chen J, Zhen X. Modulation of $\mathrm{Ca}^{2+}$ signals by phosphatidylinositol-linked novel $D_{1}$ dopamine receptor in hippocampal neurons. J Neurochem 2006; 98: 1316-23.

20 Undieh AS. Pharmacology of signaling induced by dopamine $D_{1}$-like receptor activation. Pharmacol Ther 2010; 128: 37-60.

21 Andringa G, Stoof JC, Cools AR. Sub-chronic administration of the dopamine $D_{1}$ antagonist SKF 83959 in bilaterally MPTP-treated rhesus monkeys: stable therapeutic effects and wearing-off dyskinesia. Psychopharmacology (Berl) 1999; 146: 328-34.

22 Gnanalingham KK, Hunter AJ, Jenner P, Marsden CD. Selective dopamine antagonist pretreatment on the antiparkinsonian effects of benzazepine $D_{1}$ dopamine agonists in rodent and primate models of Parkinson's disease - the differential effects of $D_{1}$ dopamine antagonists in the primate. Psychopharmacology (Berl) 1995; 117: 403-12.

23 Zhang H, Ma L, Wang F, Chen J, Zhen X. Chronic SKF83959 induced less severe dyskinesia and attenuated L-DOPA-induced dyskinesia in 6-OHDA-lesioned rat model of Parkinson's disease. Neuropharmacology 2007; 53: 125-33.

24 Zhen X, Goswami S, Friedman E. The role of the phosphatidylinositollinked $D_{1}$ dopamine receptor in the pharmacology of SKF83959. Pharmacol Biochem Behav 2005; 80: 597-601.

25 Yu Y, Wang JR, Sun PH, Guo Y, Zhang ZJ, Jin GZ, et al. Neuroprotective effects of atypical $D_{1}$ receptor agonist SKF83959 are mediated via $D_{1}$ receptor-dependent inhibition of glycogen synthase kinase-3 beta and a receptor-independent anti-oxidative action. J Neurochem 2008; 104: 946-56.

26 Chu HY, Wu Q, Zhou S, Cao X, Zhang A, Jin GZ, et al. SKF83959 suppresses excitatory synaptic transmission in rat hippocampus via a 
dopamine receptor-independent mechanism. J Neurosci Res 2011; 89: 1259-66.

27 Chen XQ, Zhang J, Neumeyer JL, Jin GZ, Hu GY, Zhang A, et al. Arylbenzazepines are potent modulators for the delayed rectifier $\mathrm{K}^{+}$ channel: a potential mechanism for their neuroprotective effects. PLoS One 2009; 4: e5811.

28 Chu HY, Yang Z, Zhao B, Jin GZ, Hu GY, Zhen X. Activation of phosphatidylinositol-linked $\mathrm{D}_{1}$-like receptors increases spontaneous glutamate release in rat somatosensory cortical neurons in vitro. Brain Res 2010; 1343: 20-7.

29 Zheng YY, Guo L, Zhen XC, Li JQ. Synthesis and antidepressant activity of arylalkanol-piperidine derivatives as triple reuptake inhibitors. Eur J Med Chem 2012; 54: 123-36.

30 Zhao G, Li S, Qin GW, Fei J, Guo LH. Inhibitive effects of Fructus Psoraleae extract on dopamine transporter and noradrenaline transporter. J Ethnopharmacol 2007; 112: 498-506.

31 Porsolt RD, Le Pichon M, Jalfre M. Depression: a new animal model sensitive to antidepressant treatments. Nature 1977; 266: 730-2.

32 Steru L, Chermat R, Thierry B, Simon P. The tail suspension test: a new method for screening antidepressants in mice. Psychopharmacology (Berl) 1985; 85: 367-70.

33 Iversen L. Neurotransmitter transporters: fruitful targets for CNS drug discovery. Mol Psychiatry 2000; 5: 357-62.

34 Chen Z, Skolnick P. Triple uptake inhibitors: therapeutic potential in depression and beyond. Expert Opin Investig Drugs 2007; 16: 1365-77.

35 Tran P, Skolnick P, Czobor P, Huang NY, Bradshaw M, McKinney A, et al. Efficacy and tolerability of the novel triple reuptake inhibitor amitifadine in the treatment of patients with major depressive disorder: a randomized, double-blind, placebo-controlled trial. J Psychiatr Res 2012; 46: 64-71.

36 Guiard BP, El Mansari M, Blier P. Prospect of a dopamine contribution in the next generation of antidepressant drugs: the triple reuptake inhibitors. Curr Drug Targets 2009; 10: 1069-84. 